UNDERGRADUATE RESEARCH IN NATURAL AND CLINICAL SCIENCE AND TECHNOLOGY (URNCST) JOURNAL Read more URNCST Journal articles and submit your own today at: https://www.urncst.com

\title{
Sleepy and Anxious: Sleep and State/Trait Anxiety and Anxiety Disorders in Adolescents and Young Adults - A Literature Review
}

\author{
Petra Fayad, BSc Student [1]*, Marwa Hussein, BSc Student [1], Safa Hussein, BSc Student [1] \\ [1] Department of Arts and Sciences, University of Toronto, Toronto, Ontario, Canada M3J 1P9 \\ *Corresponding Author: petra.fayad@mail.utoronto.ca
}

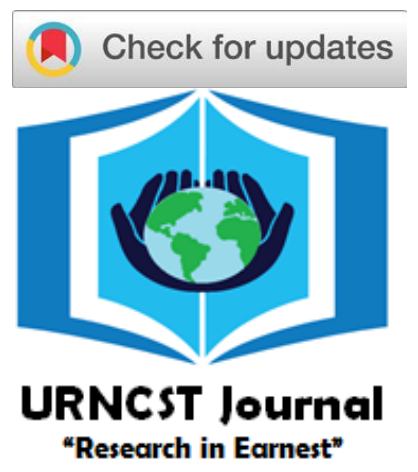

\begin{abstract}
Introduction: Sleep deprivation is a growing global concern, especially in adolescents and younger adults. Specifically, research on the loss of sleep has shown various negative consequences in neurobiological and cognitive functions. Sleep disturbances and mental health disorders have been linked, with sleep disturbances being a symptom of/risk factor for various mental health disorders. However, the relationship between sleep and anxiety remains unclear. The purpose of this review is to investigate the relationship between sleep deprivation and anxiety, namely, its role in state anxiety, trait anxiety, and the formation of anxiety disorders in adolescents and younger adults.

Methods: Primary sources of literature were found through the PubMed and Web of Science databases. Articles investigating the relationship between sleep deprivation, state/trait anxiety and anxiety disorders from within the last two decades were chosen and reviewed.

Results: The literature shows that acute sleep deprivation is linked to increased state anxiety with adolescents being disproportionately vulnerable to the consequences of a lack of quality sleep. Studies show that individuals with higher trait anxiety have poorer sleep quality which may negatively affect emotional processing. The exact nature of the relationship between sleep deprivation and anxiety disorder development is mixed, but the available literature suggests that the relationship is reciprocal.

Discussion: Although there has been an established link between anxiety and sleep deprivation, the mechanisms through which these occur need to be further understood. Findings suggest that sleep quality is affected by a change in the HPA-axis, which can increase cortisol production, a change that has been associated with poorer processing speed. It was also found that adolescents, especially early adolescents, are more vulnerable to the emotional consequences of sleep deprivation than adults are. An expansion of the current literature is required to understand the relationship between sleep and anxiety disorders.

Conclusion: More research in this field for younger populations is required to develop effective preventative measures and treatments for anxiety. Future studies should also consider a multiple disciplinary approach from social and developmental research to fully understand the factors that affect sleep in adolescents and its relationship to anxiety and anxiety disorders.
\end{abstract}

Keywords: sleep; sleep loss; sleep deprivation; trait anxiety; state anxiety; anxiety disorders

\section{Introduction}

Sleep is a basic human need as it is essential to our mental, physical, and emotional health and daily functioning. Despite the overwhelming evidence of the importance of sleep and its vital roles, there has been a well-documented global decrease in sleep duration, to the point that it has been deemed a growing "epidemic of sleep deprivation," especially in adolescents and younger adults [1]. The last three to four decades have seen a drastic shortening of sleep duration per night [2]. This decline is alarming as literature has consistently linked sleep deprivation to adverse and lifethreatening health issues, including reduced immune function, cognitive impairment, hypertension, and diabetes [2]. Adolescents have experienced a notable increase in sleep deprivation transnationally, with some estimates reaching

Fayad et al. | URNCST Journal (2021): Volume 5, Issue 9

DOI Link: https://doi.org/10.26685/urncst.255 about $25 \%$ in some countries up to a staggering $84 \%$ in others [2].

Adolescents also experience a shift in their sleep-wake cycle, where they tend to sleep later at night and wake up later in the day compared to pre-adolescents [3]. The maturation of the adolescent brain is structurally and functionally vulnerable to sleep because adolescence is a critical period for cognitive, emotional, and social development [4]. However, many adolescents fail to accommodate this shift due to early wake times from external commitments, such as school or extracurriculars [3].

Sleep stages can be separated into rapid eye movement (REM), where dreaming occurs, and non-REM, where deep sleep occurs [5]. Good quality sleep occurs with a regular pattern of three to five cycles of these two types of sleep, allowing new neural pathways to form and facilitating 
UNDERGRADUATE RESEARCH IN NATURAL AND CLINICAL SCIENCE AND TECHNOLOGY (URNCST) JOURNAL Read more URNCST Journal articles and submit your own today at: https://www.urncst.com

healthy brain functioning. [5]. These new pathways improve memory, problem-solving skills, and emotional and behavioural regulation [6]. The development of these critical cognitive functions is especially crucial for adolescents and young adults, whose brains are still in the process of maturation [7]. In addition, this population is particularly vulnerable to the effects of sleep because they are still in the process of brain maturation and the effects of sleep deprivation can lead to a higher susceptibility to long-term sleep problems [7]. This may have substantial implications in daily functioning and both physical and mental health [7].

Anxiety can be further understood in terms of typical feelings of state and trait anxiety and can also manifest in pathological levels of anxiety, as in the case of anxiety disorders. State anxiety is defined as a transient reaction of nervousness, stress, and worry that fluctuates in response to a stressor [8]. Physiological responses such as increased heart rate or perspiration are characteristic of state anxiety [8]. In contrast, trait anxiety is a personality trait that describes the "baseline" anxiety level or predisposition of an individual to anxious states [8]. From an evolutionary perspective, anxiety is a necessary reaction that triggers the fight-or-flight response that is essential to our survival; therefore, some levels of state and trait anxiety are beneficial to our daily functioning [9]. However, in the case of anxiety disorders, unnecessary heightened levels of state and trait anxiety in response to an inappropriate stressor can have negative consequences, as it can limit the decision-making process while also decreasing information processing, leading to an increase in errors due to uninformed decisions [9].

Anxiety disorders are a class of psychiatric disorders described in the Diagnostic and Statistical Manual of Mental Disorders, Fifth Edition (DSM-5) [10]. Symptoms of anxiety disorders often impede normal functioning in developing social, professional, and interpersonal relationships. Generalized Anxiety Disorder (GAD) is the excessive and ongoing worry that interferes with everyday life [11]. Social Anxiety Disorder (SAD) is the persistent fear of being watched or judged by others, and phobias are the extreme form of one specific fear [12]. Panic Disorder (PD) is characterized by sudden and unwarranted feelings of terror, Obsessive-Compulsive Disorder (OCD) is characterized by the need to perform repetitive behaviours with uncontrollable or unwanted thoughts, and Post-traumatic Stress Disorder (PTSD) is a result of a terrifying event that leads to flashbacks and nightmares [13-15]. Excessive worry may make it harder to sleep throughout the night, while a lack of sleep can also exacerbate feelings of anxiety and fear, creating a vicious cycle between sleeplessness and anxiety.

The purpose of this literature review is to investigate how sleep quality in adolescents and young adults may influence their levels of state or trait anxiety and its influence on the risk of anxiety disorder development. We expect that sleep deprivation may predict or predispose individuals to

Fayad et al. | URNCST Journal (2021): Volume 5, Issue 9 DOI Link: https://doi.org/10.26685/urncst.255 increased state and trait anxiety while also heightening one's risk of anxiety disorders.

\section{Methods}

We conducted a literature search targeting studies investigating the relationship between sleep deprivation, state/trait anxiety, and anxiety disorders among adolescents and young adults. We searched the databases from PubMed, Web of Science, and the University of Toronto libraries for literature. The inclusion criteria required: a publication date within the last two decades, written in English, and peerreviewed. The exclusion criteria included conference abstracts and brief research reports. Independent studies were prioritized over literature reviews, but not excluded. Studies that were deemed outside the research scope (e.g., examining drug effects, interactions with technology, studies of depression or mood disorders other than anxiety) were excluded from this review. Important keywords included in the search consisted of "sleep deprivation" OR "sleep loss" AND "state anxiety" OR "trait anxiety" OR "anxiety disorders" AND "adolescents" OR “young adults".

Two co-authors examined the suitability of each paper concerning the research aim and were blind to each others' assessments. If a conflict in suitability arose, then such articles were assessed by a third blind co-author.

After accounting for inclusion and exclusion criteria, four articles were reviewed for state anxiety, three for trait anxiety, and three for anxiety disorders. Study characteristics for the ten articles analyzed in this paper are presented in Table 1 for reference.

\section{Results}

$\underline{\text { State Anxiety }}$

The deleterious effects of heightened state anxiety have compelled a better understanding of their contributing factors, such as sleep deprivation and sleep loss. Sleep deprivation has been observed to have a considerable effect on mood, with several studies finding that it has been linked to decreased positive affect [1]. Recent studies have further explored the relationship between sleep deprivation and heightened state anxiety $[1,16]$. Bean and Ciesla studied ninety-four late-adolescent undergraduates where they used the daily diary method and the State-Trait Anxiety Inventory (STAI) Form-X to measure state anxiety [17]. They found that partial sleep deprivation resulted in participants reporting higher levels of anxious arousal, indicating that partial sleep loss may have an increased effect on the physical symptoms of anxiety [17].

In exploring time of day effects on the relationship between sleep deprivation and state anxiety, Cox et al. found that decreased Total Sleep Time (TST) was related to subsequent anxiety. Undergraduate students underwent actigraphy, an objective sleep measure that estimates sleep and wake by measuring motion [16]. The Consensus Sleep Diary (CSD), which asks participants about their sleep, and the Morningness-Eveningness Questionnaire (MEQ), which 
UNDERGRADUATE RESEARCH IN NATURAL AND CLINICAL SCIENCE AND TECHNOLOGY (URNCST) JOURNAL Read more URNCST Journal articles and submit your own today at: https://www.urncst.com

controls for individual differences in circadian rhythms, were also methods used in this study [16]. State anxiety was measured three times a day in the morning, afternoon, and evening over seven days by asking the question: "How anxious do you feel?" [16]. They found that decreased TST relative to the individual's average predicted subsequent anxiety [16]. They then found that the effects of sleep deprivation followed a recovery model, where the highest reports of anxiety were in the morning and afternoon, with a subsequent decrease in the evening [16].

In their observations of both adolescents and adults, Talbot et al. found that adolescents are uniquely affected by sleep deprivation. The participants were early adolescents, mid-adolescents, late-adolescents, and adults [1]. They used the sleep diary and actigraphy to measure sleep, the Stanford Sleepiness Scale to measure subjective sleepiness, and the Positive and Negative Affect Schedule (PANAS) to measure emotional affect [1]. They found that both adolescents and adults did not generate more worries or experience longer catastrophizing sequences (a cognitive overreaction that causes one to jump to the worst possible conclusion) and attributed this to decreased cognitive function [1]. When sleep-deprived, adolescents were rated higher in the likelihood of catastrophizing and more likely to experience higher state anxiety [1]. Sleep-deprived early adolescents specifically rated their most threatening worry as significantly more threatening than sleep-deprived adults [1].

Reddy et al. also investigated how sleep restriction specifically impacted adolescents. They separated the adolescents into groups of either sleep restriction (4 hours of sleep) or idealized sleep ( 9.5 hours of sleep) [18]. They used actigraphy to measure sleep, the Positive and Negative Affect Schedule for Children (PANAS-C) to measure positive and negative affect, and the State-Trait Anxiety Inventory for Children (STAIC) to assess state anxiety [18]. They performed laboratory tasks to measure emotional reactivity and regulation [18]. The study found that adolescents suffered from increased reactivity to negative images compared to the well-rested group [18]. Their findings suggest that the reason for this increase in anxiety may be due to decreased emotional regulation in this period of development [18].

\section{Trait Anxiety}

Several studies have shown the negative effects of high trait anxiety on sleep quality. Labad et al. looked at the relationship between sleep quality, cognitive functioning, and trait anxiety. They focused on adults who had no history of mental illness but scored low on the General Health Questionnaire-28 (GHQ-28), a self-report questionnaire that assesses symptoms of anxiety, depression, and insomnia [6]. Using a Neuropsychological Assessment Battery (NAB), they found that poor sleep quality was associated with poorer performance in verbal and visual memory, processing speed, and executive functioning [6]. They also performed a saliva cortisol test to determine whether the Hypothalamic-

Fayad et al. | URNCST Journal (2021): Volume 5, Issue 9 DOI Link: https://doi.org/10.26685/urncst.255
Pituitary-Adrenal (HPA) axis activity had an effect on sleep quality and found that abnormalities in the HPA axis may cause an increase in cortisol that contribute to poorer processing speed [6].

Another study by Hovaárth et al. on 1083 adults between the ages of 29 and 55 with varying sleep disorders used the STAI scores. This study also used polysomnography, a method that monitors physiological measures such as heart rate, breathing rate, and eye movements while asleep. Hovaárth et al. also used the Beck Depression Inventory (BDI), a questionnaire for depressive symptoms such as feelings of guilt and failure, insomnia, and weight loss before and after treatment [8]. They found that state anxiety increased sleep onset latency, the time it takes to fall asleep, and that trait anxiety influenced the number of REM stages during the night. They found that the number of REM stages was lower in groups with high trait anxiety compared to groups with low trait anxiety [8].

A study by Goldstein et al. investigated the effect of sleep deprivation on neural activity of the anterior insula and the amygdala using Magnetic Resonance Imaging, a neuroimaging measure of brain activity using strong magnetic fields and radio waves. Eighteen young adults between the ages of 18 and 30 performed a series of emotional-anticipatory tasks before and after sleep deprivation while brain activity was monitored. The emotional-anticipatory task involved presenting an anticipatory cue, followed by a picture stimulus, which could be one of three types: negative, neutral, or ambiguous. They found that the sleep-deprived participants had the greatest increase in anticipatory signaling in the insula activity across all stimuli and exhibited the highest trait anxiety [19]. Therefore, sleep deprivation is suggested to be influenced by higher levels of trait anxiety. Interestingly, trait anxiety was only associated with the right insula, not with the left insula or the amygdala [19].

\section{Anxiety Disorders}

Anxiety disorders have been linked to clinical sleep disorders in terms of symptoms and comorbidity. Studies have operationalized the symptoms of sleep deprivation with the term Sleep-Related Problems (SRPs), which include trouble sleeping, fatigue, nightmares, excess sleep, and inability to sleep alone. As found in a study by Chase and Pincus, there is a strong relationship between anxiety disorders and sleep disturbances in children aged 6 to 18 with an anxiety disorder. The study used a modified version of the Diagnostic and Statistical Manual of Mental Disorders, Fourth Edition (DSM-IV) with Anxiety Disorders Interview Schedule for DSM-IV, Child and Parent Versions (ADISIV-C/P). Chase and Pincus used a sleep composite scale of three different measures: the Multidimensional Anxiety Scale for Children (MASC), the Children's Depression Inventory (CDI), and the Child Behavior Checklist (CBCL).

The MASC is a questionnaire that assesses different anxiety-related phenomena in children, while the Children's 
UNDERGRADUATE RESEARCH IN NATURAL AND CLINICAL SCIENCE AND TECHNOLOGY (URNCST) JOURNAL Read more URNCST Journal articles and submit your own today at: https://www.urncst.com

Depression Inventory (CDI) is a self-report assessment of depression in children and adolescents. The Child Behavior Checklist (CBCL) is a parent rating scale for the frequency of emotional issues for those aged 6-18 [20]. Chase and Pincus' composite used the questions from each of these measurements that they deemed either have a clear relationship to child anxiety or represent the diagnostic criteria for the relevant anxiety disorders [20]. This interview provides the framework for classifying anxiety disorders and identifying their symptoms using both a child and parent interview [20]. They found that the number of anxiety disorders is directly correlated to the number of SRPs and the prevalence of SRPs in children with anxiety disorders varies depending on the type of anxiety disorder [20]. Therefore, the number of anxiety disorders has an additive risk of SRPs in children. However, there was no difference in the number of SRPs among children, preadolescents, or adolescents [20]. They found that there was also no difference in SRPs among those prescribed medication and those that were not [20].

A study investigating the relationship between short sleep duration and anxiety disorders in children and adolescents found a unidirectional relationship between sleep duration and risk for anxiety disorders [21]. This study measured anxiety using the DSM-IV diagnostic criteria for various anxiety disorders, including GAD, PD, PTSD, and social phobia (SP) and the Diagnostic Interview Schedule for Children, Version IV (DISC-IV) [21]. Sleep duration was measured through validated sleep questionnaires regarding symptoms of disturbed sleep, including average hours of sleep on weekdays and weeknights [21]. This study defined short sleep duration as less than or equal to 6 hours [21]. Roberts found that consistently reduced sleep quantity among adolescents aged 11 to 17 increased the risk of anxiety disorders, but anxiety disorders did not increase the risk for short sleep duration.

In contrast to these findings, a review paper by Brown et al. found that there is a reciprocal relationship between sleep and emotional regulation, and therefore between sleep and anxiety disturbances. The review found that poor sleep is associated with poorer emotional functioning, a possible risk factor for mental health problems [22].

Table 1. Summary of studies included for review.

\begin{tabular}{|c|c|c|c|c|c|}
\hline Authors & Type & $\begin{array}{c}\text { Sample Age } \\
\text { Range } \\
\text { (years) }\end{array}$ & $n=$ & Measures & Key Findings \\
\hline $\begin{array}{l}\text { Talbot et } \\
\text { al. [1] }\end{array}$ & $\begin{array}{l}\text { State } \\
\text { Anxiety }\end{array}$ & $\begin{array}{l}10-16,30- \\
60\end{array}$ & 44,20 & $\begin{array}{ll}\text { - } & \text { Sleep Diary } \\
\text { - } & \text { Actigraphy } \\
\text { - } & \text { PANAS-C } \\
\text { - } & \text { DSM - IV }\end{array}$ & $\begin{array}{l}\text { Early adolescents reported the subject of } \\
\text { their most threatening worry was higher } \\
\text { in the sleep-deprived state; this was not } \\
\text { found in mid-adolescents or adults }\end{array}$ \\
\hline $\begin{array}{l}\text { Labad et } \\
\text { al. [6] }\end{array}$ & $\begin{array}{l}\text { Trait } \\
\text { Anxiety }\end{array}$ & $18-65$ & 203 & $\begin{array}{ll}\text { - } & \text { GHQ-28 } \\
\text { - } & \text { NAB } \\
\text { - } & \text { Saliva Cortisol } \\
& \text { Test }\end{array}$ & $\begin{array}{l}\text { Poor sleep quality was associated with } \\
\text { poorer performance in memory, } \\
\text { processing speed, and executive } \\
\text { functioning } \\
\text { Abnormalities in the HPA axis may } \\
\text { negatively affect processing speed by } \\
\text { increasing cortisol production }\end{array}$ \\
\hline $\begin{array}{l}\text { Hovaárth } \\
\text { et al. [8] }\end{array}$ & $\begin{array}{l}\text { Trait } \\
\text { Anxiety }\end{array}$ & $29-55$ & 1083 & $\begin{array}{ll}\text { - } & \text { STAI } \\
\text { - } & \text { Polysomnography } \\
\text { - } & \text { BDI }\end{array}$ & $\begin{array}{l}\text { Trait anxiety had an effect on the } \\
\text { number of REM stages } \\
\text { The number of REM stages was lower } \\
\text { in groups with high trait anxiety, } \\
\text { compared to groups with low trait } \\
\text { anxiety } \\
\text { - State anxiety increased sleep onset } \\
\text { latency }\end{array}$ \\
\hline
\end{tabular}


UNDERGRADUATE RESEARCH IN NATURAL AND CLINICAL SCIENCE AND TECHNOLOGY (URNCST) JOURNAL Read more URNCST Journal articles and submit your own today at: https://www.urncst.com

\begin{tabular}{|c|c|c|c|c|c|}
\hline Authors & Type & $\begin{array}{c}\text { Sample Age } \\
\text { Range } \\
\text { (years) }\end{array}$ & $\mathbf{n}=$ & Measures & Key Findings \\
\hline $\begin{array}{l}\text { Cox et al. } \\
{[16]}\end{array}$ & $\begin{array}{l}\text { State } \\
\text { Anxiety }\end{array}$ & $\begin{array}{l}\text { Majority } \\
18-22\end{array}$ & 151 & $\begin{array}{ll}\text { - } & \text { Actigraphy } \\
\text { - } & \text { CSD } \\
\text { - } & \text { Insomnia Severity } \\
& \text { Index (ISI) } \\
\text { - } & \text { MEQ } \\
\text { - } & \text { Momentary } \\
& \text { Anxiety }\end{array}$ & $\begin{array}{l}\text { Decreased TST relative to personal } \\
\text { average predicts subsequent anxiety } \\
\text { - Times of day moderated the effects of } \\
\text { sleep deprivation, followed a recovery } \\
\text { model } \\
\text { - Younger adults reported higher state } \\
\text { anxiety than expected }\end{array}$ \\
\hline $\begin{array}{l}\text { Bean et al. } \\
{[17]}\end{array}$ & $\begin{array}{l}\text { State } \\
\text { Anxiety }\end{array}$ & $18-34$ & 94 & $\begin{array}{ll}\text { - } & \text { STAI-XS } \\
\text { - } & \text { Mini-MASC }\end{array}$ & $\begin{array}{l}\text { - An increase in negative physiological } \\
\text { sensations was related to anxiety } \\
\text { - No increase in the cognitive symptoms } \\
\text { of panic }\end{array}$ \\
\hline $\begin{array}{l}\text { Reddy et } \\
\text { al, [18] }\end{array}$ & $\begin{array}{l}\text { State } \\
\text { Anxiety }\end{array}$ & $13-17$ & 42 & $\begin{array}{ll}\text { - } & \text { Actigraphy } \\
\text { - } & \text { PANAS-C } \\
\text { - } & \text { STAI-C }\end{array}$ & $\begin{array}{l}\text { - Sleep restriction was associated with a } \\
\text { significant decrease in positive affect } \\
\text { - Sleep restriction elicited increased } \\
\text { anxiety and an increase in emotional } \\
\text { reactivity }\end{array}$ \\
\hline $\begin{array}{l}\text { Goldstein } \\
\text { et al. [19] }\end{array}$ & $\begin{array}{l}\text { Trait } \\
\text { Anxiety }\end{array}$ & $18-30$ & 18 & $\begin{array}{ll}\text { - } & \text { MRI } \\
\text { - } & \text { Emotional } \\
\text { anticipatory task }\end{array}$ & $\begin{array}{l}\text { The sleep-deprived group had the } \\
\text { greatest increase in anticipatory } \\
\text { signaling in the insula across negative, } \\
\text { neutral, and ambiguous picture stimuli } \\
\text { Trait anxiety was higher in the sleep- } \\
\text { deprivation session than the sleep-rested } \\
\text { session }\end{array}$ \\
\hline $\begin{array}{l}\text { Chase et } \\
\text { al. [20] }\end{array}$ & $\begin{array}{l}\text { Anxiety } \\
\text { Disorders }\end{array}$ & $6-18$ & 175 & $\begin{array}{ll}\text { - } & \text { DSM - IV } \\
\text { - } & \text { ADIS-IV-C/P } \\
\text { scale componsite } \\
\text { MASC, CDI and } \\
\text { CBC }\end{array}$ & $\begin{array}{l}\text { - Positive correlation between the number } \\
\text { of anxiety disorders and the number of } \\
\text { SRPs } \\
\text { - The prevalence of SRPs in children with } \\
\text { anxiety disorders vary depending on the } \\
\text { type of anxiety disorder }\end{array}$ \\
\hline $\begin{array}{l}\text { Roberts et } \\
\text { al. [21] }\end{array}$ & $\begin{array}{l}\text { Anxiety } \\
\text { Disorders }\end{array}$ & $11-17$ & 4175 & $\begin{array}{ll}\text { - } & \text { DSM-IV } \\
\text { - } & \text { DISC-IV } \\
\text { - } & \text { Qleep } \\
& \text { Questionnaires }\end{array}$ & $\begin{array}{l}\text { - The risk of anxiety disorders increased } \\
\text { following consistent reductions in sleep } \\
\text { quantity } \\
\text { - Anxiety disorders did not increase the } \\
\text { likelihood of short sleep duration }\end{array}$ \\
\hline $\begin{array}{l}\text { Brown et } \\
\text { al. [22] }\end{array}$ & $\begin{array}{l}\text { Anxiety } \\
\text { Disorders }\end{array}$ & & & - Literature Review & $\begin{array}{l}\text { Revealed a reciprocal relationship } \\
\text { between sleep and emotional regulation } \\
\text { and also between sleep and anxiety } \\
\text { disorders } \\
\text { - Reduced emotional functioning } \\
\text { following poor sleep is a possible risk } \\
\text { factor for mental health issues }\end{array}$ \\
\hline
\end{tabular}


UNDERGRADUATE RESEARCH IN NATURAL AND CLINICAL SCIENCE AND TECHNOLOGY (URNCST) JOURNAL Read more URNCST Journal articles and submit your own today at: $\underline{\text { https://www.urncst.com }}$

\section{Discussion}

As illustrated by our review, there is an overwhelming consensus on the link between sleep deprivation and state anxiety. Both Reddy et al. and Cox et al. found that adolescents experienced increased state anxiety following sleep deprivation. However, by dividing adolescents into three age groups, Talbot et al. indicate that future research must account for the effect of maturation state on the extent of the deleterious effects of sleep deprivation. Their finding that there was a significant difference between early adolescents and mid/late adolescents further supports this claim [1].

In the studies examining trait anxiety, the consensus is that individuals with higher trait anxiety tend to have poorer sleep quality and lower cognitive functioning. Sleep deprivation is found to affect many different physiological aspects of the body. Labad et al. discovered that sleep deprivation may contribute to a disruption in the HPA axis and may therefore increase cortisol production and heart rate. This may be the body's evolutionary reaction to trigger the fight-or-flight response in an attempt to keep the individual alert at some baseline level. It is shown that a lower number of REM stages was found to contribute to sleep deprivation, which may decrease cognitive performance in numerous cognitive functions, such as decision-making, memory, and attention [8]. In addition, prior research has found that a decrease in REM stages may decrease the brain's responsiveness to emotional experiences [23]. According to Goldstein et al., trait anxiety affects mainly the right insula but has no effect on the left insula. However, potential explanations as to how this affects sleep habits were not offered. Future research should aim to explain this differential finding in relation to sleep.

The findings regarding the relationship between sleep and anxiety disorders in adolescents and young adults show a consistent reciprocal relationship. These studies have established a connection between early SRPs and the later development of anxiety issues. Poor sleep habits may lead to poorer emotional functioning, which may be a risk factor for the development of anxiety disorders. There seems to be some discrepancy in which specific aspects of sleep are affected by anxiety disorders. For example, it was found that anxiety disorders do not affect the duration of sleep in younger cohorts [21]. However, anxiety disorders may still influence sleep deprivation through multiple other factors that impact sleep quality, such as timing. Therefore, this study is not in direct opposition to other studies in the field but rather provides a deeper understanding of this relationship.

The current literature available regarding sleep, adolescents and young adults, and anxiety disorders are severely lacking. More research targeting SRPs in adolescents with anxiety disorders is recommended. The current studies involving adolescents in this field do not take into account the sleep stages of development. This makes it difficult to consistently identify symptoms of sleep

Fayad et al. | URNCST Journal (2021): Volume 5, Issue 9 DOI Link: https://doi.org/10.26685/urncst.255 disturbances because child development is associated with the development of healthy sleep behaviours, therefore making it difficult to account for individual variability. As such, the current standardized measures of sleep are inadequate for adolescents and young adults. As shown through the usage of sleep composite scales by Chase and Pincus, the current standardized sleep measures do not account for variability in development and individuality nor do they seem adequate for the current state of the literature.

The current studies have found a reciprocal relationship between sleep deprivation and the development of anxiety disorders, but the true nature of this relationship is unclear. Future studies should systematically investigate the factors that influence sleep quality and affect its relationship with anxiety disorders. These studies should also explore the social structures that may promote sleep deprivation within the adolescent and young adult populations. This calls for a multidisciplinary approach in understanding the contributing factors that may account for this increase in sleep deprivation within this population. Understanding the link between anxiety and sleep deprivation further emphasizes the need for this understanding as it may better allow these populations to gain the support they require, especially in education.

The vague nature of the exclusion criteria and the lack of literature for this population raises some concern. The papers reviewed lacked specificity in terms of types of anxiety disorders, as well as demographic variables, such as age, sex, and education. Future research should take variables such as these into account to fully understand the relationship between sleep deprivation, state anxiety, trait anxiety, and specific anxiety disorders. Furthermore, the scope of the current review is limited given this lack of literature, and because only three databases were used in the initial search for relevant papers.

\section{Conclusions}

Understanding the relationship between sleep deprivation, anxiety, and anxiety disorders is important in anxiety treatment. The current treatments for anxiety disorders in adolescents and young adults have no impact on the number of SRPs in individuals [20]. As such, not only is the literature for adolescents and young adults lacking in this field, so are the treatments proposed. It is essential that these issues are addressed, considering that unhealthy sleep behaviours in adolescence can persevere throughout adulthood. Failure to recognize the gravity of this issue will make it abundantly easier for sleep deprivation to continue to affect every aspect of society. It is clear that the consequences of sleep deprivation have wide-reaching implications, and contributions should be explored in various fields, therefore calling for a multidisciplinary approach to its study. 
UNDERGRADUATE RESEARCH IN NATURAL AND CLINICAL SCIENCE AND TECHNOLOGY (URNCST) JOURNAL Read more URNCST Journal articles and submit your own today at: https://www.urncst.com

\section{List of Abbreviations Used}

ADIS-IV-C/P: anxiety disorders interview schedule for DSM-IV, child and parent versions

BDI: beck depression inventory

CBCL: child behavior checklist

CDI: children's depression inventory

CSD: consensus sleep diary

DISC-IV: diagnostic interview schedule for children, version IV

DSM-IV: diagnostic and statistical manual of mental

disorders, version IV

GAD: generalized anxiety disorder

GHS: German health survey

GHQ-28: general health questionnaire-28

HPA: hypothalamic-pituitary-adrenal

MASC: multidimensional anxiety scale for children

MEQ: morningness-eveningness questionnaire

OCD: obsessive compulsive disorder

PANAS: positive and negative affect schedule

PANAS - C: positive and negative affect schedule for

children

PCS: physical component score

PD: panic disorder

PTSD: posttraumatic stress disorder

PSQI: Pittsburgh sleep quality index

REM: rapid eye movement

SAD: social anxiety disorder

SRP: sleep related problem

STAI: state -trait anxiety inventory

STAIC: state-trait anxiety inventory for children

STAIXS: state-trait anxiety inventory-x form

TST: total sleep time

\section{Conflicts of Interest}

The authors Fayad, Hussein, and Hussein declare that they have no conflicts of interest.

\section{Ethics Approval and/or Participant Consent}

This literature review did not require ethics approval and/or participant consent.

\section{Authors' Contributions}

$\mathrm{SH}$ : contributed to the design of the review and the acquisition, analysis, and interpretation of data, drafted and revised the manuscript, and gave final approval of the version to be published.

$\mathrm{MH}$ : contributed to the design of the review and the acquisition, analysis, and interpretation of data, drafted and revised the manuscript, and gave final approval of the version to be published.

PF: contributed to the design of the review and the acquisition, analysis, and interpretation of data, drafted and revised the manuscript, and gave final approval of the version to be published.

Fayad et al. | URNCST Journal (2021): Volume 5, Issue 9 DOI Link: https://doi.org/10.26685/urncst.255

\section{Acknowledgements}

We would like to thank Ricky Chow for his assistance and guidance in the production of this paper.

\section{Funding}

This study was not funded.

\section{References}

[1] Talbot LS, Mcglinchey EL, Kaplan KA, Dahl RE, Harvey AG. Sleep deprivation in adolescents and adults: Changes in affect. Emotion. 2010 Dec;10(6):831-841. https://doi.org/10.1037/a0020138

[2] Chattu VK, Sakhamuri SM, Kumar R, Spence DW, BaHammam AS, Pandi-Perumal SR. Insufficient sleep syndrome: Is it time to classify it as a major noncommunicable disease? Sleep Science. 2018 Apr;11(2):56-64. https://doi.org/10.5935/1984-0063 .20180013

[3] Hansen M, Janssen I, Schiff A, Zee PC, Dubocovich ML. The impact of school daily schedule on adolescent sleep. Pediatrics. 2005 Jun;115(6):1555-61. https://doi.org/10.1542/peds.2004-1649

[4] Arain M, Haque M, Johal L, Mathur P, Nel W, Rais A, Sandhu R, Sharma S. Maturation of the adolescent brain. Neuropsychiatric Disease and Treatment. 2013 Apr;9:449-461. https://doi.org/10.2147/NDT.S39776

[5] National Heart, Lung, and Blood Institute [Internet]. Sleep deprivation and deficiency. [cited 2021 Mar 29]. Available from: https://www.nhlbi.nih.gov/healthtopics/sleep-deprivation-and-deficiency

[6] Labad J, Salvat-Pujol N, Armario A, Cabezas Á, Arriba-Arnau A, Nadal R et al. The role of sleep quality, trait anxiety and hypothalamic-pituitaryadrenal axis measures in cognitive abilities of healthy individuals. International Journal of Environmental Research and Public Health. 2020 Oct;17(20):7600. https://doi.org/10.3390/ijerph17207600

[7] Arain M, Haque M, Johal L, Mathur P, Nel W, Rais A, Sandhu R, Sharma S. Maturation of the adolescent brain. Neuropsychiatric Disease and Treatment. 2013;9:449-461. https://doi.org/10.2147/NDT.S39776

[8] Hovaárth A, Montana X, Lanquart JP, Hubain P, Szücs A, Linkowski P, Loas G. Effects of state and trait anxiety on sleep structure: A polysomnographic study in 1083 subjects. Psychiatry Research. 2016 Oct;244:279-83. https://doi.org/10.1016/j.psychres.2016 .03 .001

[9] Runyon M, Buelow M. Risky decision-making and delusion proneness: An initial examination. Heliyon. 2019 Nov;5(11):e02767. https://doi.org/10.1016/j .heliyon.2019.e02767

[10] Kupfer DJ. Anxiety and DSM-5. Dialogues in Clinical Neuroscience. 2015 Sept;17(3):245-246. https://doi.org/10.31887/DCNS.2015.17.3/dkupfer 
UNDERGRADUATE RESEARCH IN NATURAL AND CLINICAL SCIENCE AND TECHNOLOGY (URNCST) JOURNAL Read more URNCST Journal articles and submit your own today at: https://www.urncst.com

[11] Mayo Clinic [Internet]. Generalized anxiety disorder Symptoms and causes. [cited 2021 Apr 2]. Available from: https://www.mayoclinic.org/diseases-conditions/ generalized-anxiety-disorder/symptoms-causes/syc20360803

[12] Mayo Clinic [Internet]. Social anxiety disorder (social phobia) - Symptoms and causes. [cited 2021 Apr 2]. Available from: https://www.mayoclinic.org/diseasesconditions/social-anxiety-disorder/symptomscauses/syc-20353561

[13] Mayo Clinic [Internet]. Panic attacks and panic disorder - Symptoms and causes. [cited 2021 Apr 2]. Available from: https://www.mayoclinic.org/diseasesconditions/panic-attacks/symptoms-causes/syc20376021

[14] Mayo Clinic [Internet]. Obsessive-compulsive disorder (OCD) - Symptoms and causes. [cited 2021 Apr 2]. Available from: https://www.mayoclinic.org/diseasesconditions/obsessive-compulsive-disorder/symptomscauses/syc-20354432

[15] Mayo Clinic [Internet]. Post-traumatic stress disorder (PTSD) - Symptoms and causes. [cited 2021 Apr 2]. Available from: https://www.mayoclinic.org/diseasesconditions/post-traumatic-stress-disorder/symptomscauses/syc-20355967

[16] Cox RC, Sterba SK, Cole DA, Upender RP, Olatunji BO. Time of day effects on the relationship between daily sleep and anxiety: An ecological momentary assessment approach. Behaviour Research and Therapy. 2018 Dec;111:44-51. https://doi.org/10.1016/ j.brat.2018.09.008
[17] Bean CA, Ciesla JA. Naturalistic partial sleep deprivation leads to greater next-day anxiety: The moderating role of baseline anxiety and depression. Behavior Therapy. 2021;52(4):861-73. https://doi.org/ 10.1016/j.beth.2020.10.008

[18] Reddy R, Palmer CA, Jackson C, Farris SG, Alfano CA. Impact of sleep restriction versus idealized sleep on emotional experience, reactivity and regulation in healthy adolescents. Journal of Sleep Research. 2017 Aug;26(4):516-525. https://doi.org/10.1111/jsr.12484

[19] Goldstein AN, Greer SM, Saletin JM, Harvey AG, Nitschke JB, Walker MP. Tired and apprehensive: Anxiety amplifies the impact of sleep loss on aversive brain anticipation. The Journal of Neuroscience. 2013 Jun;33(26):10607-15. https://doi.org/10.1523/ JNEUROSCI.5578-12.2013

[20] Chase R, Pincus DB. Sleep-related problems in children and adolescents with anxiety disorders. Behavioral Sleep Medicine. 2010 Dec;9(4):224-236. https://doi.org/10.1080/15402002.2011.606768

[21] Roberts R, Duong H. Is there an association between short sleep duration and adolescent anxiety disorders? Sleep Medicine. 2016 Feb;30:82-87. https://doi.org/ 10.1016/j.sleep.2016.02.007

[22] Brown W, Wilkerson A, Boyd S, Dewey D, Mesa F, Bunnell B. A review of sleep disturbance in children and adolescents with anxiety. Journal of Sleep Research. 2017 Nov;27(3). https://doi.org/10.1111/ jsr. 12635

[23] Walker MP, van der Helm E. Overnight therapy? The role of sleep in emotional brain processing. Psychological Bulletin. 2009 Sep;135(5):731-48. https://doi.org/10.1037/a0016570

\section{Article Information}

Managing Editor: Jeremy Y. Ng

Peer Reviewers: Ricky Chow, Pallavi Dutta

Article Dates: Received Apr 02 21; Accepted Aug 07 21; Published Sep 2421

\section{Citation}

Please cite this article as follows:

Fayad P, Hussein M, Hussein S. Sleepy and anxious: Sleep and state/trait anxiety and anxiety disorders in adolescents and young adults - A literature review. URNCST Journal. 2021 Sep 24: 5(9). https://urncst.com/index.php/urncst/article/view/255 DOI Link: https://doi.org/10.26685/urncst.255

\section{Copyright}

(C) Petra Fayad, Marwa Hussein, Safa Hussein. (2021). Published first in the Undergraduate Research in Natural and Clinical Science and Technology (URNCST) Journal. This is an open access article distributed under the terms of the Creative Commons Attribution License (https://creativecommons.org/licenses/by/4.0/), which permits unrestricted use, distribution, and reproduction in any medium, provided the original work, first published in the Undergraduate Research in Natural and Clinical Science and Technology (URNCST) Journal, is properly cited. The complete bibliographic information, a link to the original publication on http://www.urncst.com, as well as this copyright and license information must be included. 


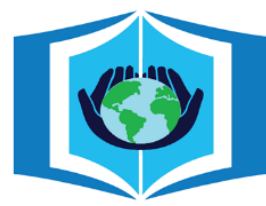

\section{URNCST Journal \\ "Research in Earnest"}

\section{Funded by the \\ Government of Canada}

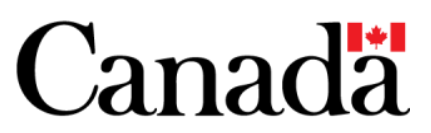

Do you research in earnest? Submit your next undergraduate research article to the URNCST Journal!

| Open Access | Peer-Reviewed | Rapid Turnaround Time | International | | Broad and Multidisciplinary | Indexed | Innovative | Social Media Promoted |

Pre-submission inquiries? Send us an email at info@ urncst.com | Facebook, Twitter and LinkedIn: @URNCST

Submit YOUR manuscript today at https://www.urnest.com! 